\title{
Who gets hooked on Facebook? An exploratory typology of problematic Facebook users
}

\author{
Tracii Ryan', John Reece ${ }^{2}$, Andrea Chester ${ }^{3}$, Sophia Xenos ${ }^{4}$ \\ ${ }^{1}$ School of Health Sciences, RMIT University, Melbourne, Australia \& Faculty of Education, Monash University, Clayton, \\ Australia \\ ${ }^{2}$ School of Psychological Sciences, Australian College of Applied Psychology, Melbourne, Australia \\ ${ }^{3}$ School of Design and Social Context, RMIT University, Melbourne, Australia \\ ${ }^{4}$ School of Health Sciences, RMIT University, Melbourne, Australia
}

\begin{abstract}
Scholars have suggested that there are multiple pathways to problematic Facebook use, and each are linked to the types of activities that users engage in. However, these concepts have yet to be empirically explored. The present paper addresses this gap in the literature by presenting a pilot study based on a sample of 59 (50 females, 9 males) problematic Facebook users. Closed and open-ended data were collected using an online survey. Cluster analysis was then used to identify three types of problematic Facebook users: those with high engagement in social activities and browsing, those with low engagement in social activities but high engagement in browsing, and those with low engagement in both social activities and browsing, but moderate engagement in gaming. This paper presents an in depth discussion of the patterns of behavior identified within these clusters. In addition, four potential pathways to problematic Facebook use are proposed: online social enhancement, social monitoring, procrastination, and entertainment. This study contributes to the development of a much-needed theoretical framework of problematic Facebook use, and provides direction for future research.
\end{abstract}

Keywords: problematic Facebook use; social networking sites; addiction; internet; typologies

\section{Introduction}

The development of compulsive internet use, and the negative outcomes associated with it, are generally considered to be indicative of internet addiction (Caplan, 2005; Greenfield, 1999; van den Eijnden, Meerkerk, Vermulst, Spijkerman, \& Engels, 2008). Griffiths (1999) conceptualises internet addiction as a behavioral addiction; a term that is used to refer to cases of non-substance-based addictive symptomatology. While many empirical studies of internet addiction do not distinguish between different types of online activities (e.g., Bozoglan, Demirer, \& Sahin, 2013; Hawi, 2012; Tonioni et al., 2012), some online behavioral addictions experts recognise that the problematic use of social networking sites (SNSs; Kuss \& Griffiths, 2011; Yu, Hsu, Yu, \& Hsu, 2012), for example, is dissimilar to internet gaming disorder (DiChiara, 2010; Hsu, Wen, \& Wu, 2009). It is important for mental health experts to recognise this divergence, as there are likely to be different etiologies, predictors, and treatments for these various forms of disordered Internet use. 
The notion that internet addiction takes different forms was originally proposed by Young, Pistner, O'Mara, and Buchanan (1999). These researchers surveyed 35 therapists regarding their experiences in treating patients with internet addiction, and based on the qualitative responses, identified five specific classifications: (a) cybersexual addiction: the compulsive use of adult web sites to obtain cybersex and cyberporn; (b) cyber-relationship addiction: over-involvement in online relationships; (c) net compulsions: obsessive online gambling, shopping, or online trading; (d) information overload: compulsive web surfing or database searches; and (e) computer addiction: obsessive computer game playing.

In response to the work of Young et al. (1999), some scholars argued that many of the individuals who might meet a diagnosis for these subtypes of internet addiction are not actually addicted to the internet per se (Griffiths, 2000; Sim, Gentile, Bricolo, Serpelloni \& Gulamoydeen, 2012). Instead, they simply use the internet as a vehicle to engage in other forms of addictive behavior. On this topic, Sim et al. (2012) stated, "treating a pathological gambler's computer use is unlikely to resolve the underlying problem" (p. 749), while Griffiths (2000) posited that the term 'internet addiction' should refer only to behavior that could not occur without using the internet; specifically, addiction to computer-mediated forms of communication.

In recognition of the above concerns, Davis (2001) introduced terminology that could be used to differentiate between types of online addiction. The first, specific pathological internet use, refers to content-specific addictive use of the internet. This sort of addictive behavior is likely to continue in the absence of the internet, and is focused on a single application (e.g., online gambling, shopping, or cybersex addiction). The second, generalised pathological internet use, is predominantly associated with addiction to social uses of the internet, such as chat rooms and email. Davis (2001) remarked that the latter type of addiction is motivated by a strong need for social connectedness, which can be gratified by communicating online.

Based on Davis' (2001) typologies of online addiction, Caplan (2010) developed the social skill model of generalised pathological internet use. This model states that preferring to conduct social interaction in an online environment is a necessary requirement for internet addiction to occur. More specifically, individuals who have a preference for online social interaction use the internet as a means of escaping from negative mood states, such as loneliness or anxiety. Oftentimes, the act of engaging in online communication will alleviate the negative mood (known as mood alteration), which then causes reinforcement of the addictive behavior. Deficient selfregulation (i.e., excessive use and loss of control) may then result, leading to internet addiction.

In recent times, social uses of the internet have undergone considerable growth. In particular, the publics' interest in SNSs appears almost exponential (Smith, 2013a); membership of Facebook, for example, increased from 606 million in 2011 (Ryan \& Xenos, 2011) to 1.09 billion daily active users in 2016 (Facebook, 2016). As such, some researchers have turned their attention to the possibility that the use of SNSs could become addictive (Griffiths, Kuss, \& Demetrovics, 2014). At this stage, SNS addiction is not recognised as a legitimate disorder; however there is mounting evidence to support the notion that SNSs use can become problematic, and is associated with addictive symptoms. For example, the use of SNS can be habitual, excessive, driven by mood alteration, and motivated by the desire for social interaction, entertainment, or passing time (Ryan, Chester, Reece, \& Xenos, 2014).

Thus far, many studies of problematic SNS use have focused specifically on Facebook (e.g., Hong, Huang, Lin, \& Chiu, 2014; Zaremohzzabieh, Samah, Omar, Bolong, \& Kamarudin, 2014). This is unsurprising, considering the high proportion of Facebook use compared to other forms of SNSs. While Kuss and Griffiths (2011) posit that this singular focus on Facebook is unwarranted, we have suggested elsewhere that it is important to ascertain why this site, in particular, is so popular (Ryan et al., 2014). Furthermore, researchers should attend to the specific motivations of problematic Facebook users, as these may differ from problematic users of other SNSs (e.g., Twitter, Pinterest).

The idea that motivations for internet use are associated with the development of problematic usage patterns is based on Kardefelt-Winther's (2014) model of compensatory internet use. This model asserts that individuals are motivated to use certain online applications, such as Facebook, due to a desire to escape from unwanted moods. For example, people with social anxiety may recognise that Facebook allows them to communicate with 
others without the discomfort and embarrassment that they are used to in face-to-face scenarios. As such, these people may begin to communicate regularly on Facebook in an effort to reduce loneliness.

Another theory, known as outcome expectancies (Jones, Corbin, \& Fromme, 2001), can also be drawn upon to understand how problematic Facebook use can manifest from the reduction of undesirable mood states. Eventually, individuals rely on Facebook use to alleviate their negative moods and this behaviour becomes reinforced. At this point, individuals may become preoccupied with using Facebook and lose control over their use. This can then lead to excessive Facebook use and negative consequences.

One of the keys to understanding the relationship between the motivations of Facebook use and the development of problematic Facebook use may be the types of activities that users engage in. For example, users can perform numerous activities on Facebook, such as gambling, game playing, and chat (Griffiths et al., 2014). As such activities are linked to the development of online addictions, and each are considered to be conceptually different, it is important to determine their relationship to the manifestation of problematic Facebook use.

At this early stage of research, it is imperative that researchers examine whether there is a relationship between different Facebook activities and the development of problematic Facebook use. As such research was a prerequisite for the development of Caplan's (2010) social skill model of pathological internet use, it may facilitate creation of a much-needed theoretical framework to support the construct of problematic Facebook use. Furthermore, if Facebook use is associated with different types of activities, such as updating profiles or checking the news feed, this would provide support for the compensatory model of internet use (KardefeltWinther, 2014). Therefore, we expect the results of this study will contribute to knowledge about potential pathways to problematic Facebook use, enable construction of valid assessment measures, and lead to the design of more appropriate interventions.

The purpose of the present paper is to address the aforementioned gap in the literature by asking the following research question: Does problematic Facebook use take different forms? However, it is important to note that problematic Facebook use is not yet a well-defined construct. While some researchers have measured problematic Facebook use or "Facebook addiction" by modifying existing measures of internet addiction (e.g., Çam \& Iş̧bulan, 2012; Hong et al., 2014; Lee, Cheung, \& Thadani, 2012), this approach is limited by the fact that there is no consensus regarding criteria or gold-standard measures. As a result, this study takes an exploratory approach to the measurement of problematic Facebook use and the development of typologies.

\section{Method}

This exploratory pilot study of problematic Facebook use employed a cross-sectional survey design. The survey was developed for this study, and included both closed and open-ended questions. Responses to open-ended questions were transformed into quantitative data in order to identify a sample of problematic Facebook users. These quantitative data were then analysed using a range of inferential statistics. Due to the limited sample size, open-ended responses were used where possible to triangulate the overall findings.

\section{Sample}

Respondents were self-acknowledged excessive Facebook users who were over the age of 18, proficient in written English, and able to access the internet independently. While a total of 461 respondents completed the survey, data from 44 respondents were removed due to drop outs $(n=36)$ or missing data $(n=8)$. The remaining 417 respondents (286 females, 131 males) ranged in age from 18 to 80 years old $(M=31.57, S D=9.33$ ). The majority resided in Australia (77\%), while the remainder lived in the United Kingdom (8\%), Ireland (5\%), Canada $(3 \%)$, or other countries (7\%). Within this larger sample, a subsample of problematic Facebook users was identified (see Procedure section for further details), comprising 59 respondents (50 females, 9 males). The majority (64\%) were aged $24-35$ and resided in Australia (81\%). Further descriptive information relating to this subsample is presented below. 


\section{Materials}

An online survey was used as part of a wider study of problematic Facebook use (see Appendix). The survey was hosted by Qualtrics (www.qualtrics.com) and consisted of 31 items: three demographic questions, four general Facebook usage questions, and 24 questions designed to measure potential symptoms of problematic Facebook use. Of these 24 items, two used five-point Likert-type scale responses, nine were dichotomous closed (yes/no) screening questions, and 13 were open-ended questions.

The open-ended items were based on seven common symptoms of internet addiction: negative consequences (undesirable outcomes related to internet use), loss of control (having trouble limiting use), online social enhancement (preference for online communication), preoccupation (persistent thoughts about using the internet), mood alteration (using the internet to escape from unwanted moods), excessive use (spending longer on the internet than intended), and withdrawal (unpleasant physical or emotional effects that occur when not using the internet).

These symptoms were selected by performing a systematic review of internet addiction instruments with sound psychometric properties and academic presence (for further information on this process see Ryan, Chester, Reece \& Xenos, 2016). It should also be noted that negative consequences was represented in the survey by two open-ended questions: one relating to interference with daily activities and the other relating to problems with personal relationships. As the construct of problematic Facebook use is still developing, open-ended questions were worded broadly to avoid relying entirely on preconceived structures of addiction.

The closed screening questions were used to establish presence of problematic Facebook use symptoms, and open-ended follow up questions were used to generate further exploration. The flow of the survey was typically configured so that the follow-up question(s) only appeared if the respondent answered 'yes' to the relevant screening question.

\section{Procedure}

Three methods of recruitment were used in this study: (a) a Facebook Ad, specifically targeted to appear on the profile pages of Facebook users who were over 18 and listed English as a known language; (b) a sharable Facebook post on the primary investigators' personal account; and (c) posts on ten online discussion boards from Australia, Canada, Ireland, and the United Kingdom. All three methods requested participation from Facebook users who felt that they used the site too much. After clicking on the survey link, potential respondents were directed to a webpage hosting an information statement and a consent form. Access to the online survey was granted after potential respondents indicated that they met the inclusion criteria and consented to taking part in the study.

\section{Measures}

To prepare for data analysis, all open-ended survey responses were recoded into quantitative variables. This process resulted in three distinct quantitative measures: the first comprised the original quantitative variables from the survey, while the second and third consisted of derived variables transformed from coded open-ended responses. These three measures will now be described in further detail.

Measure of Facebook use. In this study, Facebook use comprised four variables based on quantitative survey questions. Level of Facebook use was originally measured by asking "On average, how much time per day do you spend on Facebook (for non-work related purposes)?" Respondents were provided with seven possible answers, ranging from "30 minute or less" to "More than 8 hours". These data were then organised into four levels of usage: $1=$ light $(<31 \mathrm{mins}), 2=$ moderate $(>30 \mathrm{mins}$ to $<2 \mathrm{hrs}), 3=$ heavy $(>2 \mathrm{hrs}$ to $<4 \mathrm{hrs})$, and $4=$ very heavy $(>$ 4hrs).

Frequency of use of Facebook on mobile devices was measured using the item, "How often do you use Facebook on devices other than your computer (for non-work related purposes)?" Responses were collected using a 4point frequency scale, where $1=$ "Never" and $4=$ "Often". Level of concern about Facebook use was measured by 
asking respondents "How concerned are you about your Facebook use?" with answers ranging from 1 = "not at all concerned" to 5 = "extremely concerned". Use of Facebook to be social was measured using a 5-point Likerttype response scale (where 1 = "strongly disagree" and $5=$ "strongly agree") and the item "My Facebook usage is motivated by a desire to be social, or to feel connected to others. Descriptive data for these variables are presented in Table 1.

\begin{tabular}{lcc} 
Table 1. Means and Standard Deviations for Facebook Use Variables in the Total Sample (N=417). \\
\hline Facebook Use Variable & $\boldsymbol{M}$ & SD \\
\hline Level of Facebook use & 2.21 & .95 \\
Frequency of Facebook use on mobile devices & 3.20 & 1.06 \\
Level of concern about Facebook use & 1.61 & .87 \\
Use Facebook to be social & 3.86 & .89 \\
\hline
\end{tabular}

Preliminary measure of problematic Facebook use. To identify problematic Facebook users, two raters were asked to independently assess responses to the 13 open-ended questions relating to problematic Facebook use. The objective of this assessment was to identify whether the responses to the broadly worded questions were actually indicative of any of the identified symptoms of problematic Facebook use. Raters were provided with the coding criteria for each of the relevant questions, examples of quotes that should be positively coded, and exclusion criteria. It should be noted that all of the 417 included respondents provided meaningful responses to the open-ended questions, and both raters individually assessed all respondents' answers.

At this point, it became clear that the open-ended questions had failed to elicit a large enough number of responses that were indicative of loss of control (i.e., too few respondents indicated that they spent longer than intended on Facebook). This was likely due to the broad way in which this question was worded, rather than the non-existence of this symptom within the population. As a result, this symptom was excluded from further analysis. In place of loss of control, an extra coding criterion was added: self-identified recognition of problematic Facebook use. This was based on open-ended responses that revealed a level of selfacknowledgement that problematic behavioural patterns (or symptoms of addictive behaviour) were occurring in relation to Facebook use. The inclusion of this variable helped ensure that included respondents were likely to be problematic Facebook users.

To test level of agreement between raters, kappa coefficients were calculated. In line with Landis and Koch's (1977) guidelines, the acceptance level was set at .61. The following symptoms had kappa coefficients in the appropriate range: negative consequences (interference with daily activities, problems with relationships), preoccupation, mood alteration, excessive use, withdrawal, and self-identified recognition of potential problematic Facebook use (.66-.99). In contrast, the kappa coefficient for online social enhancement was only moderate (.56), which was attributed to ambiguity in some of the responses and the broadness of the coding criteria. As such, online social enhancement was excluded from further analysis.

Binary categorical variables were created for each of the remaining symptoms (negative consequences was represented by the two symptoms of interference with daily activities and problems with personal relationships). In cases where raters had disagreed about the presence of a potential indicator of problematic use, that symptom was deemed to be absent. As a result, only respondents who had been coded for the presence of a particular symptom by both coders received a score of one for that symptom. Each respondent was then given a total score for the included symptoms. In this way, the lowest score that could be received was zero (indicating absence of coded symptoms) and the highest was seven (indicating presence of all symptoms). 


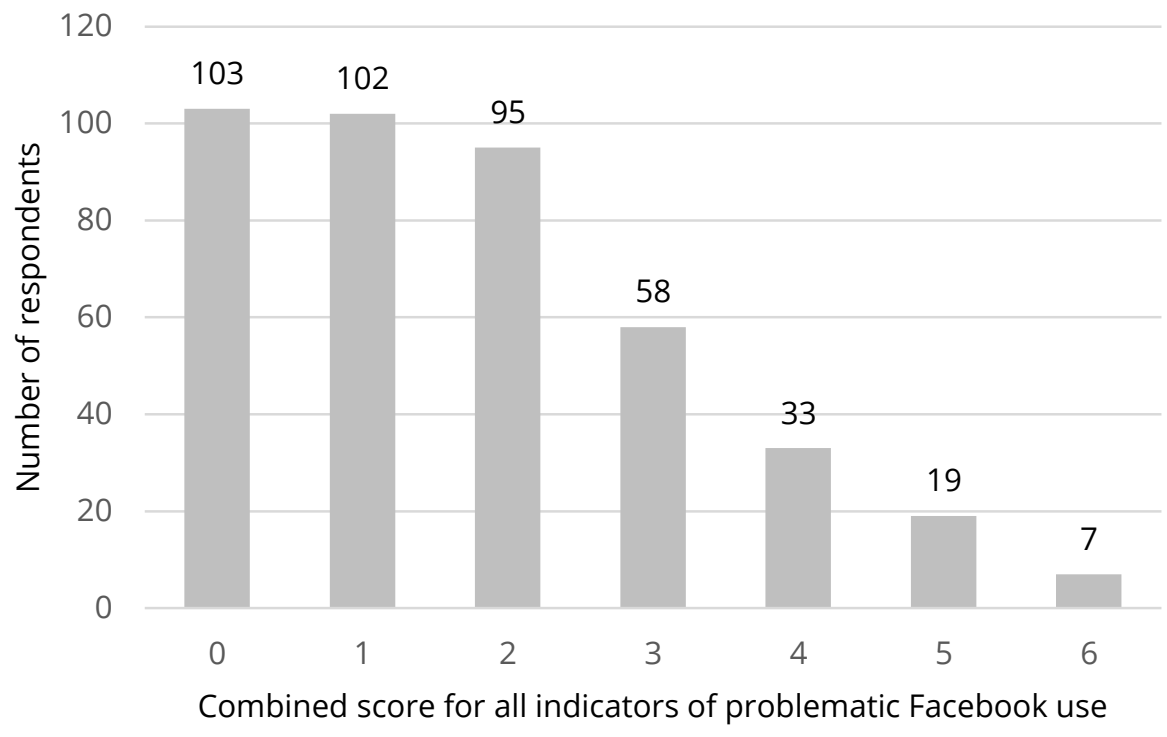

Figure 1. Distribution of scores on a preliminary measure of problematic Facebook use.

As can be seen in Figure 1, clear negative skew in the distribution of responses was evident. Even though the recruitment criteria requested participation from individuals who felt that they use Facebook too much, it was likely that only a minority of respondents would show evidence of multiple indicators of problematic Facebook use. This is partly due to the fact that the questions were worded in a broad manner, and partly because the prevalence of online addictions is generally low (Kuss, Griffiths, Karila, \& Billieux, 2013).

In the absence of any normative data or guidelines from previous research, a number of criteria were considered when deciding on a cut-off point for identifying problematic Facebook use. A cut-off point of four was selected, as this score identified respondents who scored in the top quartile of the sample. It also resulted in a sample of 59 problematic Facebook users, which was an adequate sample size to allow further statistical analyses to be performed (discussed in further detail below). Even though reducing the cut-off point to three would have resulted in a larger sample, it was felt that the higher score identified a more clinically interesting group of respondents.

To further support our decision to set the cut-off point at four symptoms, the differences between problematic Facebook users (i.e., those with a score of four or more on the potential measure of Facebook use) and nonproblematic Facebook users (i.e., those with a score of three or less) on the demographic variables and the measure of Facebook use were examined. Country of residence was excluded from any further analysis as a high proportion of problematic Facebook users were Australian. A series of $t$-tests was performed on each scale or ordinal variable: age, level of Facebook use, frequency of using Facebook on mobile devices, level of concern about Facebook use, and level of agreement that Facebook is used for social purposes. As sex was a categorical variable, analysis was performed using a $\chi^{2}$ test of independence.

The $\chi^{2}$ test of independence (using Yates' Correction for Continuity) revealed a significant relationship between problematic Facebook users and non-problematic Facebook users for $\operatorname{sex}^{2} \chi^{2}(1, N=417)=7.48, p=.006, \varphi=$ .14 , indicating that women are more likely to be problematic Facebook users than men. Furthermore, as shown in Table 2, the group of problematic Facebook users was more likely than the group of non-problematic Facebook users to be heavier Facebook users, to use Facebook more frequently on mobile devices, and to have higher levels of concern about their Facebook use. There were no significant differences between the groups for age or desire to use Facebook to be social. Taken together, these results support the notion of heterogeneity between the two groups, and provide further support for the applying the cut-off score of four. 
Table 2. Descriptive and Inferential Analysis of Differences between Problematic Facebook Users $(n=59)$ and Non-Problematic Facebook Users $(n=358)$ on Demographic and Facebook Use Variables.

\begin{tabular}{|c|c|c|c|c|c|c|c|}
\hline Variable & $M$ & $S D$ & $t$ & $d f$ & $p$ & $g$ & $\mathrm{Cl}(95 \%)$ \\
\hline Age & & & 0.93 & 93.25 & .35 & 0.11 & $-1.5,3.6$ \\
\hline Non-problematic users & 31.71 & 9.61 & & & & & \\
\hline Problematic users & 30.69 & 7.43 & & & & & \\
\hline Level of Facebook use & & & -5.92 & 415 & $<.001$ & 0.83 & $-1.01,-.51$ \\
\hline Non-problematic users & 2.10 & 0.93 & & & & & \\
\hline Problematic users & 2.86 & 0.82 & & & & & \\
\hline \multicolumn{3}{|c|}{ Frequency of Facebook use on mobile devices } & -2.25 & 80.93 & .03 & 0.30 & $-.61,-.04$ \\
\hline Non-problematic users & 3.15 & 1.07 & & & & & \\
\hline Problematic users & 3.47 & 1.01 & & & & & \\
\hline Level of concern about Facebook use & & & -8.77 & 415 & $<.001$ & 1.13 & $-1.2,-.76$ \\
\hline Non-problematic users & 1.47 & .78 & & & & & \\
\hline Problematic users & 2.46 & .88 & & & & & \\
\hline Use Facebook to be social & & & -1.18 & 415 & .24 & 0.15 & $-.39, .10$ \\
\hline Non-problematic users & 3.84 & 0.86 & & & & & \\
\hline Problematic users & 3.98 & 1.06 & & & & & \\
\hline
\end{tabular}

Within this newly identified sample of problematic Facebook users, 86\% experienced preoccupation, $83 \%$ had concerns about their own Facebook use, 66\% had withdrawal symptoms when not using Facebook, 51\% used Facebook excessively, and 32\% used Facebook for mood alteration. With respect to the incidence of negative consequences, $91 \%$ reported that Facebook use interfered with their daily activities and $46 \%$ had experienced problems in their relationship due to Facebook use.

Inventory of Facebook activities. In the online survey, respondents were asked one open-ended question regarding how they usually spent their time when they were using Facebook. The first author (TR) coded responses to this question using thematic analysis, and created binary quantitative variables for each of the most commonly performed activities. As further inferential analyses would be focused on problematic Facebook users, only open-ended responses from this subsample were recoded.

Table 3. Frequencies and Percentages of Themes Emerging from Responses Regarding Facebook Activities.

\begin{tabular}{llll}
\hline Theme & Example responses & $\boldsymbol{n}^{\boldsymbol{a}}$ & $\mathbf{\%}$ \\
\hline Browsing content & Checking updates, looking at photos & 48 & 81 \\
Social interaction & $\begin{array}{l}\text { Commenting on friends' posts, replying to } \\
\text { comments, using messenger }\end{array}$ & 43 & 73 \\
Games & Playing games & 9 & 15 \\
Posting updates & Posting to my timeline & 8 & 14 \\
Shopping & Buying from Facebook based businesses & 6 & 10 \\
Notifications & Checking for responses to posts & 3 & 5 \\
Competitions & Entering competitions & 2 & 3 \\
\hline
\end{tabular}

Note: ${ }^{\text {a }}$ The $n$ refers to the number of respondents who gave a response coded within this theme, and not the number of references. 
As Table 3 illustrates, seven common types of use emerged. The strongest themes, endorsed by the majority of the sample, were browsing content and social interaction. A smaller, but still sizable, proportion of the sample mentioned regularly playing games on Facebook, posting updates, or shopping. In contrast, only a small percentage of the sample indicated that they regularly checked notifications or entered competitions on Facebook.

\section{Data Analysis}

Cluster analysis was used to answer the primary research question of whether problematic Facebook use takes different forms. Cluster analysis is a multivariate method of data reduction that creates homogenous clusters of individuals by appraising inter-relationships among selected variables (Burns \& Burns, 2008). Individuals within clusters are expected to be more similar to each other than they are to individuals in other clusters (Digre, Reece, Johnson, \& Thomas, 2009). In this way, it was possible to examine whether groups of problematic Facebook users performed Facebook activities that were distinct from other groups of problematic users.

When performing the cluster analysis, Schwarz's Bayesian Criterion was used in preference to Akaike's Information Criterion as the primary clustering algorithm, as the latter tends to overestimate the number of clusters (Mooi \& Sarstedt, 2011). A log-likelihood distance measure was used, and the number of clusters was determined automatically. Two-step cluster analysis was selected as the most appropriate procedure, as it is the only form of cluster analysis in which categorical variables can be easily incorporated (i.e., without the need for dummy variable coding; Brophy, Reece, \& McDermott, 2006).

Although cluster analysis is an exploratory procedure (Burns \& Burns, 2008), it is important that the selection of included variables is theoretically or conceptually justifiable (Mooi \& Sarstedt, 2011). Generally, where researchers have discriminated between different types of internet or problematic Facebook use (e.g., Davis, 2001; Griffiths, 2012; Young et al., 1999), they have done so according to the main type of activities engaged in (e.g., shopping, gambling, gaming). Therefore, for this particular cluster analysis, it seemed appropriate that the included variables were related to Facebook activities.

To increase the chances of obtaining a stable and interpretable clustering solution, the sample size used in the analysis should be substantially greater than the number of included variables. Formann (1984, cited in Mooi \& Sarstedt, 2011) recommends that the sample size exceeds $2 m$, where $m$ represents the total number of included variables. Based on a sample size of 59, the optimum number of included variables according to Formann's guidelines is five. Therefore, the five most frequently endorsed variables (i.e., those endorsed by at least $10 \%$ of the sample) were included in the analysis: browsing content, social interactions, games, posting updates, and shopping. The resulting outcome was an interpretable three-cluster solution, in which all respondents were successfully incorporated.

\section{Results}

Cluster 1 was the largest cluster, comprising 30 (51\%) individuals. Of the members of this cluster, 100\% browsed content, $100 \%$ were socially active, and $10 \%$ posted updates. These individuals seem to be heavily involved in connecting and maintaining their existing social relationships on Facebook, through both actively engaging and observing. As such, this cluster was named high social engagement, high browsing.

Cluster 2 consisted of 17 (29\%) individuals, of which 100\% browsed content on Facebook, 35\% shopped, 18\% engaged socially, $12 \%$ played games, and $6 \%$ updated. These individuals performed a variety of activities on Facebook, but seem to be primarily motivated by browsing content rather than actively engaging in social activities. This cluster was therefore referred to as low social engagement, high browsing.

Cluster 3 was the smallest cluster, comprising $12(20 \%)$ individuals. Of the members of this cluster, 58\% played games, 33\% updated, 17\% were social, and $8 \%$ browsed content. Unlike the two other clusters, individuals grouped into Cluster 3 did not appear to be primarily motivated by browsing Facebook for new content, nor did they appear to want to directly engage with their Facebook friends. Instead, the majority played games on Facebook. This cluster was named low social engagement, moderate gaming. 
Frequencies and inferential statistics for the quantitative variables are presented in Table 4. With regard to the inferential statistics, a series of Kruskal-Wallis Non-Parametric ANOVAs was performed to look for differences among the clusters on each of the ordinal variables (i.e., age group and Facebook use variables). There were no statistically significant differences among the three clusters for age group, level of Facebook use, use of Facebook on mobile devices, level of concern, or socially motivated use. To look for associations between clusters for the binary categorical variables (sex, and the potential indicators of problematic Facebook use) a series of $\chi^{2}$ tests of independence was performed. There were no statistically significant associations between the three clusters for sex, preoccupation, mood alteration, withdrawal, negative consequences (which comprised problems with personal relationships and interference with daily activities), excessive use, or self-recognition of problem.

Table 4. Frequencies (with Percentages) and Results of Inferential Statistics for Cluster Members on Demographic, Facebook Usage, and Potential Problematic Facebook Use Variables.

\begin{tabular}{|c|c|c|c|}
\hline Variables & $\begin{array}{l}\text { HSE-HB } \\
(n=30)\end{array}$ & $\begin{array}{l}\text { LSE-HB } \\
(n=17)\end{array}$ & $\begin{array}{r}\text { LSE-MG } \\
(n=12)\end{array}$ \\
\hline \multicolumn{4}{|l|}{ Demographics } \\
\hline \multicolumn{4}{|l|}{ Sex } \\
\hline Female & $25(83)$ & $13(77)$ & $12(100)$ \\
\hline \multirow[t]{2}{*}{ Male } & $5(17)$ & $4(23)$ & $0(0)$ \\
\hline & \multicolumn{3}{|c|}{$\chi^{2}(2, n=59)=3.10, p=.21$, Cramer's V $=.23$} \\
\hline
\end{tabular}

Age group

$\begin{array}{lccc}18-23 & 6(20) & 2(12) & 1(8) \\ 24-29 & 9(30) & 7(41) & 2(17) \\ 30-35 & 8(26) & 7(41) & 5(42) \\ 36-41 & 5(17) & 0(0) & 1(8) \\ 42+ & 2(7) & 1(6) & 3(25)\end{array}$

\section{Facebook Use}

Level of Facebook use

$$
\begin{aligned}
& \text { Light (<30 mins) } \\
& \text { Moderate ( } 30 \text { mins - } 2 \text { hrs) } \\
& \text { Heavy ( } 2-4 \text { hrs) } \\
& \text { Very Heavy (4+ hrs) }
\end{aligned}
$$

Frequency of Facebook use on mobile devices

Never
Rarely
Sometimes
Often

Level of concern about Facebook use

None
Mild
Moderate
Very
Extreme

Use Facebook to be social

Strongly Disagree

Disagree

Neither Agree nor Disagree

Agree

Strongly Agree

$\begin{array}{ccc}0(0) & 2(12) & 0(0) \\ 8(27) & 8(47) & 4(33) \\ 16(53) & 3(18) & 3(25) \\ 6(20) & 4(23) & 5(42) \\ & \chi^{2}(2, n=59)=3.27, \mathrm{p}=.20 \\ 3(10) & 3(18) & 1(8) \\ 1(3) & 0(0) & 0(0) \\ 2(7) & 5(29) & 1(8) \\ 24(80) & 9(53) & 10(84) \\ & \chi^{2}(2, n=59)=4.08, p=.13 & \end{array}$

$\begin{array}{ccc}4(13) & 1(6) & 1(8) \\ 17(57) & 8(47) & 5(42) \\ 7(23) & 6(35) & 5(42) \\ 2(7) & 1(6) & 0(0) \\ 0(0) & 1(6) & 1(8) \\ & \chi^{2}(2, n=59)=.2 .22, p=.33\end{array}$

$\begin{array}{ccc}3(10) & 1(6) & 0(0) \\ 1(3) & 0(0) & 0(0) \\ 3(10) & 2(12) & 1(8) \\ 13(44) & 9(53) & 7(59) \\ 10(33) & 5(29) & 4(33) \\ & \chi^{2}(2, n=59)=.40, p=.82 & \end{array}$




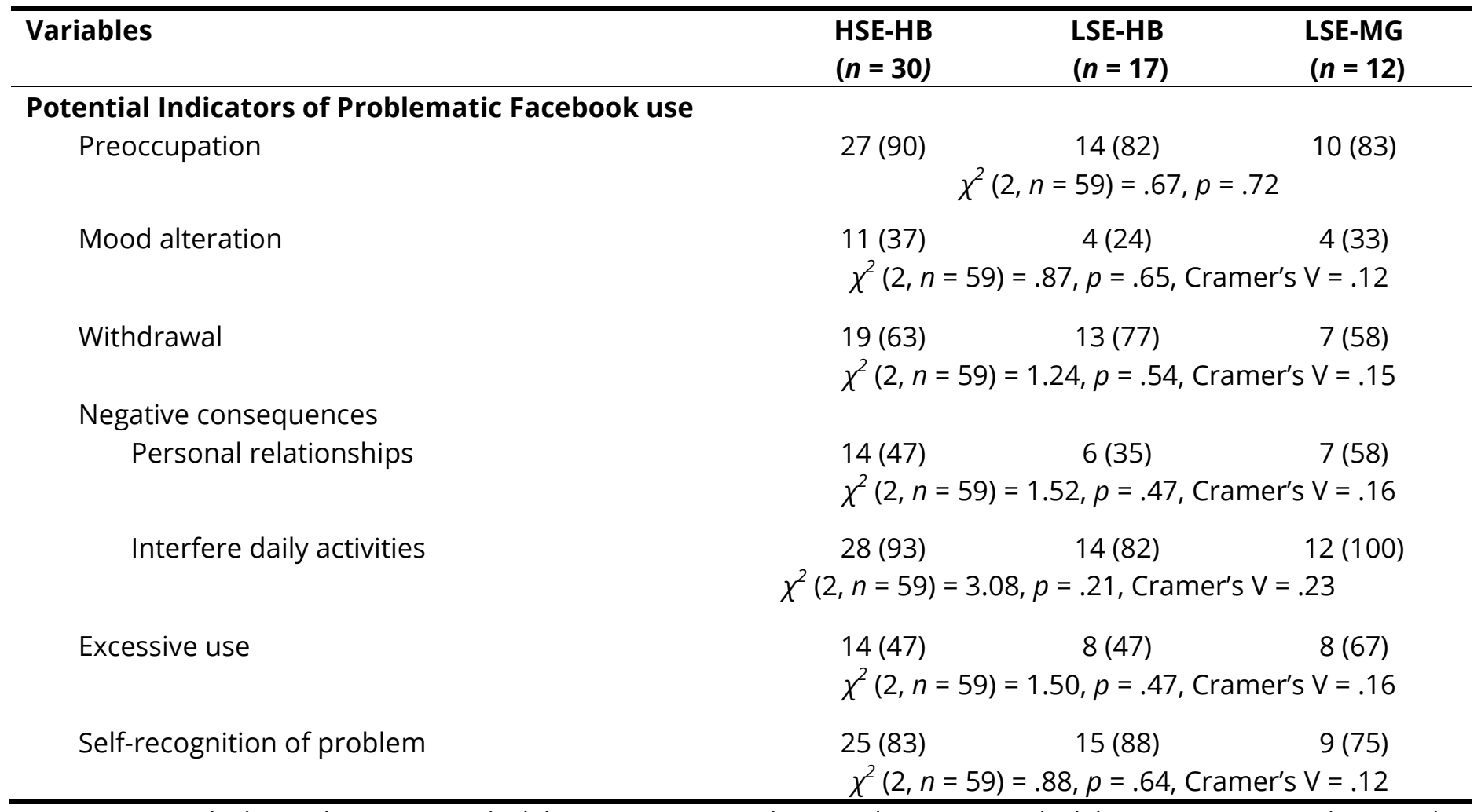

Note: HSE-HB = high social engagement-high browsing, LSE-HB = low social engagement-high browsing, LSE-MG = low social engagement-moderate gaming.

The absence of any significant differences among clusters can be considered an artefact of low statistical power. As such, we examined descriptive results and effect sizes to see whether there were any notable differences, despite the lack of statistical significance. To calculate effect sizes for the ordinal variables, pairwise comparisons were conducted using Mann-Whitney $U$ Tests and the effect size, $r$, was calculated. To calculate effect sizes for binary categorical variables, Cramer's $\mathrm{V}$ was used (as reported above). In the interests of brevity, only comparisons with at least close-to-medium effect sizes are discussed further. In interpreting these effect sizes, we were guides by Cohen's (1988) criteria. For Cramer's V, a small effect $=.07$, a medium effect $=.21$, and a large effect $=.35$. For $r$, a small effect $=.10$, a medium effect $=.30$, a large effect $=.50$, and a very large effect $=.70$.

Considering the differences between level of Facebook use for the HSE-HB and LSE-HB clusters, $r=.23$, and the LSE-HB and LSE-MG clusters, $r=.27$, the effect sizes for both of these comparisons were close-to-medium. Only $41 \%$ of respondents in the LSE-HB cluster reported heavy or very heavy Facebook use, compared with $73 \%$ and $67 \%$ in the HSE-HB and LSE-MG clusters respectively (see Table 4).

Similarly, when considering differences between use of Facebook on mobile devices for the HSE-HB and LSE-HB clusters, $r=.25$, and the LSE-HB and LSE-MG, $r=.29$, the effect sizes for both of these comparisons were closeto-medium. Only $53 \%$ of respondents in the LSE-HB cluster used Facebook on mobile devices often, compared with $80 \%$ and $84 \%$ in the HSE-HB and LSE-MG clusters respectively (see Table 4).

The effect size for the association between cluster membership and both sex and interference with daily activities was $V=.23$, which signifies a medium effect. For sex, this can be accounted for by the absence of males in the LSE-MG cluster (this is supported by a standardised residual of -1.4 for that cell). For interference with daily activities, the effect may be related to the low frequency of reported interference in the LSE-HB cluster (standardised residual $=1.3$ ). 


\section{Discussion}

The aim of this pilot study was to develop an exploratory typology of problematic Facebook users. This was achieved by surveying a sample of Facebook users who felt that they used Facebook too much. From this larger sample, a sub-sample of problematic Facebook users was established using a cut-off of any four symptoms. Then, cluster analysis was used to identify three potential types of problematic Facebook users: those heavily engaged in social activities and browsing (high social engagement-high browsing), those who have low engagement in social activities but high engagement in browsing (low social engagement-high browsing), and those who have low engagement both in social activities and browsing, but moderate engagement in gaming (low social engagement-moderate gaming).

While inferential statistics did not reveal any statistically significant differences between clusters, examination of effect sizes support the potential for differences to exist. To strengthen this notion, we now further explore the descriptive and open-ended results to look for potential patterns within and between clusters. However, due to the small number of respondents within each cluster, some of these results may have occurred by chance. Therefore, all of the results discussed below require validation in follow-up studies using larger samples.

\section{High Social Engagement-High Browsing}

The majority of individuals in this cluster were women aged between 24 and 35 years who were heavy Facebook users, and often used the site on mobile devices. Most were only mildly concerned about their Facebook use, and either agreed or strongly agreed that they used Facebook to be social.

With regard to the potential indicators of problematic Facebook use, this cluster included the highest proportion of individuals coded as experiencing preoccupation with Facebook. Furthermore, most had experienced interference with daily activities because of Facebook, recognised that they had a problem with Facebook use, and had experienced withdrawal from Facebook. Less than half were coded as experiencing interference with personal relationships and excessive use. This cluster had the lowest proportion of individuals who had experienced mood alteration.

This cluster had the highest percentage of socially active Facebook users. Based on the cluster analysis alone, these individuals would appear to have a preference for online social interaction. If this is the case, Caplan's (2010) social skill model predicts that they would also use Facebook for mood alteration (i.e., from loneliness). However, individuals in this cluster had the lowest incidence of mood alteration of all three clusters. Examination of the open-ended responses relating to addictive symptoms is therefore necessary to gain a more complete picture of why problematic Facebook use may occur among these cluster members.

Thematic analysis of responses from these cluster members indicates that at least half preferred to socialise on Facebook rather than face-to-face. This appeared to be related to the desire to achieve greater levels of control over Facebook interactions. As one respondent noted, "[Facebook offers the] ability to remove what I have posted if I believe I made an error, within a few minutes of posting it." (Male, 18, heavy user). This desire for social control on Facebook may point to underlying social anxiety or shyness, but there were few comments to directly support this assumption. In addition, only three members of this cluster mentioned using Facebook due to loneliness.

Quotes revealed that, rather than using Facebook to connect with others (e.g., through comments or messages), these individuals were motivated by the desire to know whether new content has been posted. For example, "I am eager to know what others are doing [on Facebook] so I check the news feed over and over again" (Male, 19, moderate user). While individuals in this cluster may use Facebook to avoid loneliness, they have a strong desire to keep abreast of what is happening in this online social space. This may be because they feel more comfortable conversing with friends using Facebook and, therefore, have immersed themselves in their online social life more than other users.

As individuals in this cluster seemed enthusiastic about checking Facebook for new content, it is not surprising that the majority (63\%) had experienced withdrawal symptoms when they were not using Facebook. Several 
members referred directly to experiencing 'withdrawal', while others noted feeling stressed and anxious because they could not access the site. Individuals in this cluster were also the most likely to admit that, by not checking Facebook, they were failing to see important updates: "[Without Facebook I felt] annoyed, as though I were missing out on things" (Female, 32, moderate user).

It is also not surprising that regular Facebook checking seems to lead to negative consequences for these cluster members; 93\% admitted experiencing interference with daily activities. Thematic analysis revealed that work and study were the activities most commonly interrupted to use Facebook. In contrast, less than half of the individuals in this cluster admitted that Facebook had caused problems in their relationships. Of those who did, several referred to the fact that their partners did not like the fact that they often checked Facebook on their phones. For example, "My husband says I frequently zone out while he is talking to me only to jump on my smart phone to check Facebook" (Female, 24, very heavy user). A high proportion of this sample also appeared selfaware regarding their problematic Facebook use, as many comments related to excessive use or loss of control: "I use [Facebook] a lot. I'm not concerned about what I do on there, just how much I am on it." (Female, 30, moderate user).

In sum, the evidence presented here suggests that there are a group of problematic Facebook users who feel comfortable interacting on Facebook and are highly preoccupied with monitoring what is happening on the site. As a result, these individuals feel as though they are missing out when they do not check Facebook regularly, and this interferes with their ability to complete daily activities. Further research should ascertain whether online social enhancement is relevant to the development of this type of problematic Facebook use.

\section{Low Social Engagement-High Browsing}

While individuals in this cluster were predominantly women, it is worth noting that it also contained the highest proportion of men (23\%). This cluster also included the highest proportion of individuals aged 24-35. Most cluster members were moderate Facebook users, who often used the site on mobile devices, and had mild to moderate levels of concern about their use. The majority of members either agreed or strongly agreed that they used Facebook to be social.

This cluster contained the highest proportion of individuals who had experienced withdrawal, and who recognised that they had a problem with Facebook. Furthermore, the majority were coded as experiencing both preoccupation and interference with daily activities due to Facebook use. Under half of the cluster admitted being excessive users, that Facebook had interfered with their personal relationships, and that they used Facebook for the purposes of mood alteration.

Thematic analysis revealed that, like the high social engagement - high browsing cluster members, preoccupation with Facebook stemmed from a desire to know what is happening, and whether there have been any updates. For instance, "[When not using Facebook I wonder] what have I missed?" (Female, 30, very heavy user). Given that these sorts of thoughts were common in both this and the previous cluster, it is clear that preoccupation leads to high engagement with browsing Facebook. This may then cause interference with daily activities. In fact, individuals in this cluster were the most likely to refer to Facebook as a 'distraction': “[Facebook] can make me very lazy and distracted from the housework" (Female, 30, moderate user).

Unlike members of the high social engagement - high browsing cluster, individuals in this cluster did not commonly mention feeling more comfortable interacting socially on Facebook compared to face-to-face. Instead, their comments referred to the fact that Facebook communication was less intimate, less private, and more superficial. Rather than being motivated to use Facebook for active, two-way social interaction, it seems that these cluster members tend to use Facebook more passively (i.e. browsing content with commenting). Some individuals also mentioned that they used Facebook due to boredom: "I'm concerned I use [Facebook] a fair bit, but I wouldn't need to use it if I had other things to occupy my time." (Male, 25, moderate user).

The desire to use Facebook when bored could explain why these problematic Facebook users used Facebook more broadly (e.g., for shopping and games) than members of the previous cluster. We have proposed elsewhere that individuals who use Facebook to stave off boredom may be likely to develop problematic use 
through the motivation of passing time (Ryan et al., 2014). Not having access to Facebook did seem to lead to withdrawal for these individuals; the open-ended data revealed that they were likely to feel lost without Facebook, or that they were missing out. Some also mentioned experiencing negative emotions when Facebook was unavailable, such as anxiety and urges to check.

It is worth noting that few members of this cluster admitted that Facebook use had caused problems with their personal relationships. Therefore, it seems that these individuals are less likely than high social engagement high browsing members to browse or use Facebook when in the company of others. This would make sense, given that they seem to be primarily motivated by boredom or passive social activity. However, when engaging in important tasks, such as study or work, they seem more prone to distraction than individuals in other clusters. Researchers should aim to further explore the motivations for this cluster.

\section{Low Social Engagement-Moderate Gaming}

Within this final cluster, the majority of respondents were aged 24-35, were generally very heavy users, and most often used Facebook on mobile devices. Most of these individuals had mild to moderate concern about their Facebook use, and agreed or strongly agreed that their Facebook use was socially motivated. It is worth noting that this cluster was comprised entirely of women, but this is possibly a result of bias towards women in the overall sample, and the very small number of respondents within this cluster.

In terms of the potential indicators of problematic Facebook use, most of these cluster members were coded as having experienced all of them, except mood alteration. Despite this, these individuals had the highest incidence of mood alteration among all of the clusters. This cluster also had the highest proportion of members who were excessive users, who admitted that Facebook interfered with their daily Facebook activities, and caused problems with their personal relationships.

Based on the open-ended data obtained from this subset of respondents, it seems that they were the most likely to feel that Facebook communication was more comfortable than communicating offline: "I am more 'outgoing' online and shy in person" (Female, 33, very heavy user). It was also apparent that these individuals tended to use Facebook when they were bored or lonely:

I only use Facebook when I'm on my own and am bored and/or lonely. When I'm with friends or family, I'm happy to be in their company and don't consider checking Facebook. When I'm on my own, I feel the need to "fill the void" with my Facebook games and photos. (Female, 39, very heavy user)

Some cluster members elected to use Facebook instead of engaging in other activities: "There are definitely times when I should be outside enjoying the sunshine, enjoying my family, and doing study and/or chores, but instead I'm cooped up inside tapping away [on Facebook]." (Female, 39, very heavy user). This excessive use commonly led to negative consequences, such as failure to complete housework and tension with partners: "[I] spend lots of time on [Facebook] so dinner isn't cooked." (Female, 33, very heavy user).

Such quotes seem to fit within the social skill model of pathological internet use (Caplan, 2010), as does the finding that the majority of respondents in this cluster agreed that their Facebook use was socially motivated. However, these cluster members were the least likely to mention engaging in social activities on Facebook. Instead, they more frequently enjoyed playing games and updating their profile. This finding appears contradictory, but may be due to the way in which social engagement was categorised in this study (i.e. through the activities of commenting on friends' posts, replying to comments, and using messenger). It may be the case that respondents in this cluster obtained social interaction with strangers through the games that they played, rather than with their Facebook friends. As with the other findings discussed here, further research is needed to validate this assumption.

This cluster contained the highest proportion of individuals aged over 42 years, which may indicate that there is a risk of problematic gaming in users of this age group. Smith (2013b) noted a similar pattern in her study of Facebook gamers, and concluded that older adults are more likely than young people to use Facebook games to 
engage in mood alteration and online social enhancement. Due to the low sample size in this cluster, this result should be explored further.

Although the open-ended data in this cluster were limited (due to the small sample size), these problematic Facebook users may be using Facebook excessively because they are prone to boredom. Boredom has been found to be a motivator among people who become addicted to games on SNSs (Zhou \& Leung, 2012), and may stem from large amounts of unstructured time (e.g., if they are unemployed or stay-at-home parents). For example, most of these cluster members admitted that Facebook interfered with their ability to study, complete housework, or spend time with their children. In contrast, the responses from individuals in the other clusters more commonly mentioned Facebook interfering with work. However, as data relating to employment status was not collected in any phase of this study, more research is needed to confirm these patterns.

Overall, the results presented here support a number of tentative conclusions. First, high social engagement high browsing individuals seem to have a strong desire to know what is happening on Facebook, and are motivated to partake in social interaction on the site because it affords them higher levels of control over their interactions when compared to offline communication. Second, low social engagement - high browsing individuals may be distracted by Facebook and find that they become preoccupied with checking the site, particularly when feeling bored. Third, low social engagement - moderate gaming individuals may feel more confident communicating on Facebook than offline, and possibly have larger amounts of free time available to them than members of the other clusters. These particular cluster members appeared to fit most closely to the profile of an online addict, based on the symptoms that were examined.

It is worth noting that, while this study recruited a sample of Facebook users who were self-acknowledged excessive users, the majority of problematic Facebook users were only mildly or moderately concerned about their Facebook use. This may reflect an underlying attitude of denial that their Facebook use is a serious problem, despite the fact that it often led to negative consequences.

\section{Future Research: Pathways to Problematic Facebook Use}

In this study, Facebook activities were used as a basis for exploring whether there are different types of problematic Facebook users. The results implied that problematic Facebook use does take different forms, and these may be linked to a combination of activities. This finding differs from existing research related to internet addiction, which has tended to focus specifically on discrete activities (e.g., cybersex or gambling; Young et al., 1999). Furthermore, other variables - particularly those related to the motivations of Facebook use - may also contribute to heterogeneous development of problematic Facebook use.

Based on the model of compensatory internet use (Kardefelt-Winther, 2014), outcome expectancy theory (Jones et al., 2001), and the findings from this study, we propose that there are at least four potential pathways to problematic Facebook use: online social enhancement, social monitoring, procrastination, and entertainment. These pathways are now explored in more detail.

Online social enhancement. This potential pathway may stem from the tendency for Facebook use to provide a level of social interaction lacking in individuals' offline lives. Preliminary support for this pathway was found in the cluster analysis results presented here: members of the high social engagement-high browsing and low social engagement-moderate gaming clusters both indicated that they felt more comfortable communicating on Facebook than in offline situations.

This potential pathway aligns with Caplan's (2010) social skill model. It is also supported by other empirical research. For example, lonely people use Facebook to connect with others (Clayton, Osborne, Miller, \& Oberle, 2013), socially anxious people perceive increases in social support and well-being from Facebook use (Indian \& Grieve, 2014), and individuals with a preference for online social interaction can develop problematic use of Facebook (Lee et al., 2012). It is likely that this pathway does not necessitate a preference for online social interaction. Some individuals may prefer face-to-face communication, but are not able to easily achieve this due to life circumstances or geographical location. Further research is therefore needed to examine the proposed relationship between social isolation and the development of problematic Facebook use. 
It is also important to note that the model devised by Caplan (2010) encompasses various types of online social activity. Therefore, it is likely that this potential pathway to problematic use is not exclusive to Facebook use. In fact, Wan (2009) reported that loneliness was a significant predictor of problematic use of the campus-based SNS xiaonet.com, while Liu \& Wang (2012) found that loneliness was associated with the problematic use of mobile phones. Therefore, further research is recommended to assess whether this pathway might relate to various social uses of technology.

Social monitoring. This proposed pathway results from a fear of missing out (FOMO) on information when Facebook is not being used. Individuals on this pathway feel a strong need to monitor the activity of their friends by repetitively checking the News Feed for new updates. For those individuals, the repetitive behavior of checking Facebook for new updates relieves FOMO and provides a sense of connectedness and social inclusion. Through this mood alleviation, the outcome expectancy of mood alteration is reinforced. It is possible that this reinforcement occurs on a variable-ratio schedule ratio (Schoenfeld, Cumming, \& Hearst, 1956), as new content is posted on the News Feed at random intervals.

If this pathway is viable, is likely that affected individuals experience interference with work and study, as they are often distracted from these activities by checking Facebook (Przybylski, Murayama, DeHaan, \& Gladwell, 2013). They may also feel withdrawal symptoms (in the form of frustration) when no new content has been posted to Facebook since the last time they checked. Members of the high social engagement - high browsing and low social engagement - high browsing clusters of problematic Facebook users both showed a strong desire to keep up to date with new information by regularly checking Facebook. Therefore, some of these individuals potentially became problematic Facebook users via the social monitoring pathway.

References to a social monitoring pathway to problematic use have not been common in the academic literature. In one qualitative study of problematic Facebook users, a female respondent admitted that limiting her Facebook checking to once a day left her feeling overwhelmed with information (Zaremohzzabieh et al., 2014). As a result, she spent most of her time checking Facebook for updates in order to more efficiently monitor what was happening with her friends. In addition, Przybylski et al. (2013) reported that individuals who experienced FOMO were more likely to use Facebook after waking, before sleep, and during meals and lectures.

While Facebook is not the only form of SNS to provide a feature offering a real-time, continuously updating stream of information (e.g., Twitter, Linkedln do the same), it does have the largest membership base (Smith, 2013a). Therefore, it is possible that members of an individual's offline social network would be more heavily represented on Facebook than other SNSs. As such, problematic use developed via the social monitoring pathway may be highly relevant to Facebook use. Researchers should attempt to confirm that this is the case by directly examining the relationship between problematic Facebook use and FOMO. In addition, it is worth examining how the thoughts related to FOMO develop. Are they more common among individuals with certain personality traits (e.g., neurotic, extraverted), or do they occur in response to a particular life event involving Facebook (e.g., an instance of social exclusion)?

Procrastination. This pathway relates to the use of Facebook to avoid completing mundane or difficult tasks. Like the previously discussed pathways, this pattern of behavior is expected to lead to mood alteration in at-risk individuals this time through the alleviation of stress or fear of beginning a new task. As this pathway is not intrinsically linked to a need for social interaction or monitoring, it is likely to be associated with broad Facebook usage (i.e., engaging in a range of activities).

According to Davis (2001), individuals who develop generalised pathological internet use are highly likely to use the internet to procrastinate from other tasks. This theme was prominent amongst low social engagementmoderate gaming cluster members. The tendency to procrastinate is generally linked to low levels of the trait conscientiousness (Goldberg, 1990). It is worth noting that numerous studies have reported that there is an association between low levels of conscientiousness and addiction (e.g., Buckner, Castille, Sheets, 2012; Kotov, Gamez, Schmidt, \& Watson, 2010; Yang, Li, \& Mingxin, 2006). In particular, Wilson, Fornasier, and White (2010) reported that individuals with low conscientiousness had higher levels of both SNS use and addictive tendencies. In addition, it has previously been reported that Facebook users are more likely than non-users to be low on 
conscientiousness (Ryan \& Xenos, 2011). Therefore, it may be the case that low conscientiousness is linked to the development of problematic Facebook use through the procrastination pathway.

It seems then that there is a solid basis for further exploration of this potential pathway. It is important to ascertain whether individuals who fit this pattern are only using Facebook problematically, or whether they may also be demonstrating problematic engagement in other internet-related activities. Given that distraction has previously been identified as a potential symptom of generalised pathological internet use (Davis, Flett \& Besser, 2002), it is likely that task avoiders can develop problematic use of a variety of online social applications. However, if there is a subset of problematic users who are focused solely on Facebook, it is important to determine what it is about the site that is appealing to those particular individuals.

Entertainment. This potential pathway may occur when individuals have excessive free time, and elect to use Facebook as a method of entertainment. For example, several of the low social engagement - moderate gaming cluster members mentioned having nothing else to do other than use Facebook. Such individuals may potentially be unemployed, stay-at-home parents, or retired. Problematic use occurs when these individuals begin to rely on Facebook to escape from boredom, thus experiencing mood alteration.

As with the procrastination pathway, it is likely that this type of problematic use would be associated with broad Facebook usage. Furthermore, due to the excess free time these individuals have, their Facebook use may become very heavy. As researchers have identified that boredom is a common motivation among online gaming addicts (Hussain \& Griffiths, 2009; Zhou \& Leung, 2012) this potential pathway to problematic Facebook use should be explored further, particularly in relation to loss of control over Facebook games.

These pathways support the model of compensatory internet use (Kardefelt-Winther, 2014), as all are tied to different motivations for Facebook use and come about due to the desire for mood alteration. They also align with outcome expectancy theory (Jones et al., 2001), as we argue that mood alteration leads to the additional symptoms of problematic use. Based on the data collected in this study, we also suggest that the absence of Facebook use may manifest in withdrawal symptoms that are specific to each pathway (see Figure 2).

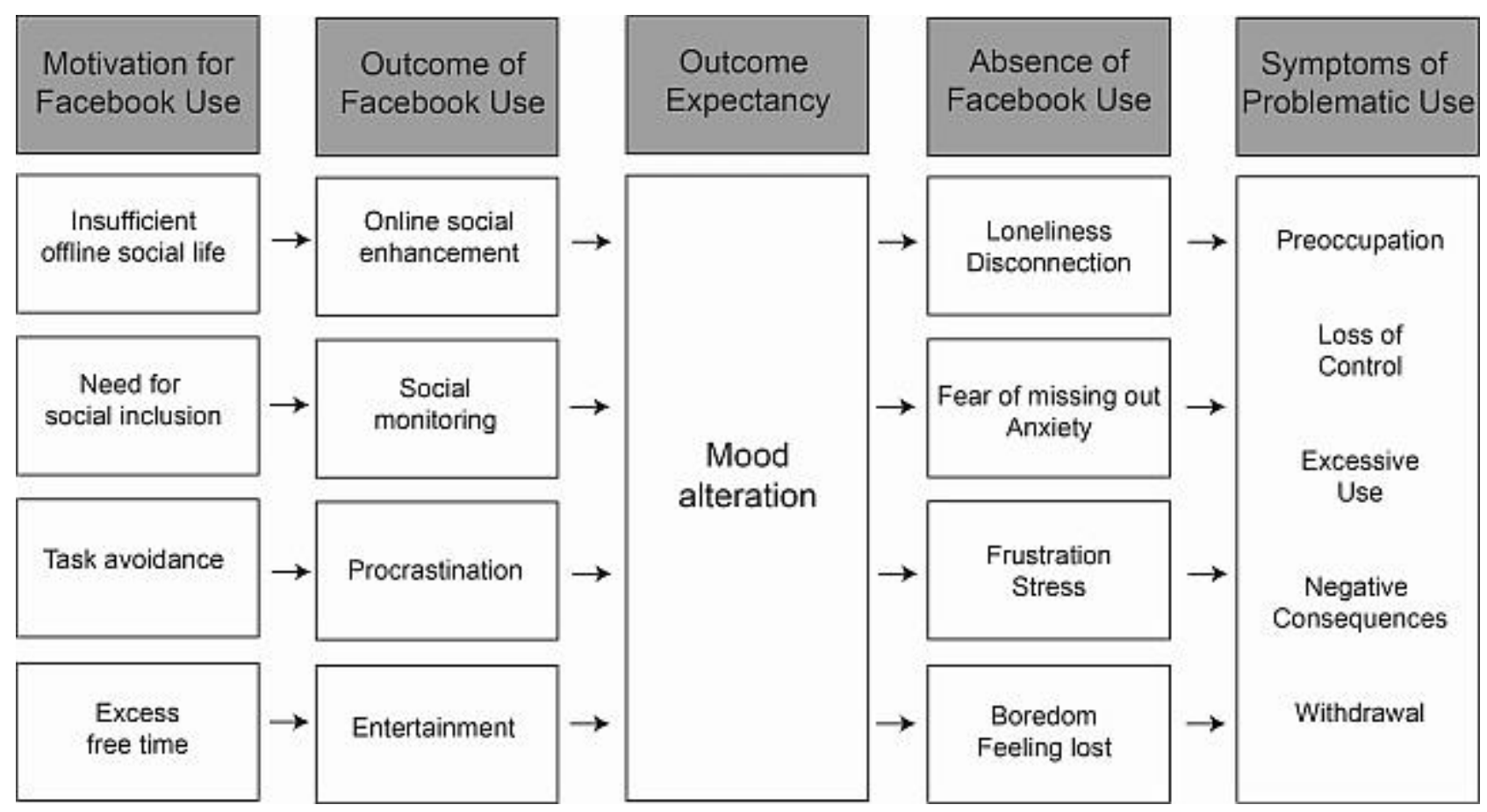

Figure 2. Four potential pathways to problematic Facebook use. 
Problematic Facebook use may also potentially occur due to a combination of pathways. This is illustrated in Figure 3 using the cluster analysis results as examples. While all four pathways are tentatively supported by the results discussed in this paper, more extensive research is needed to confirm their relevance to problematic Facebook use (and other forms of problematic online use or addiction). At this point, researchers should conduct further phenomenological studies, perhaps by interviewing self-acknowledged problematic Facebook users, to explore the validity of these four pathways. In doing so, the aim should be to tease out these users' motivations for Facebook use, the personal outcomes of Facebook use, and the feelings that occur when Facebook is not available. Research is also needed to establish whether these pathways are relevant only to Facebook use, or whether they are common to multiple forms of problematic SNS use.

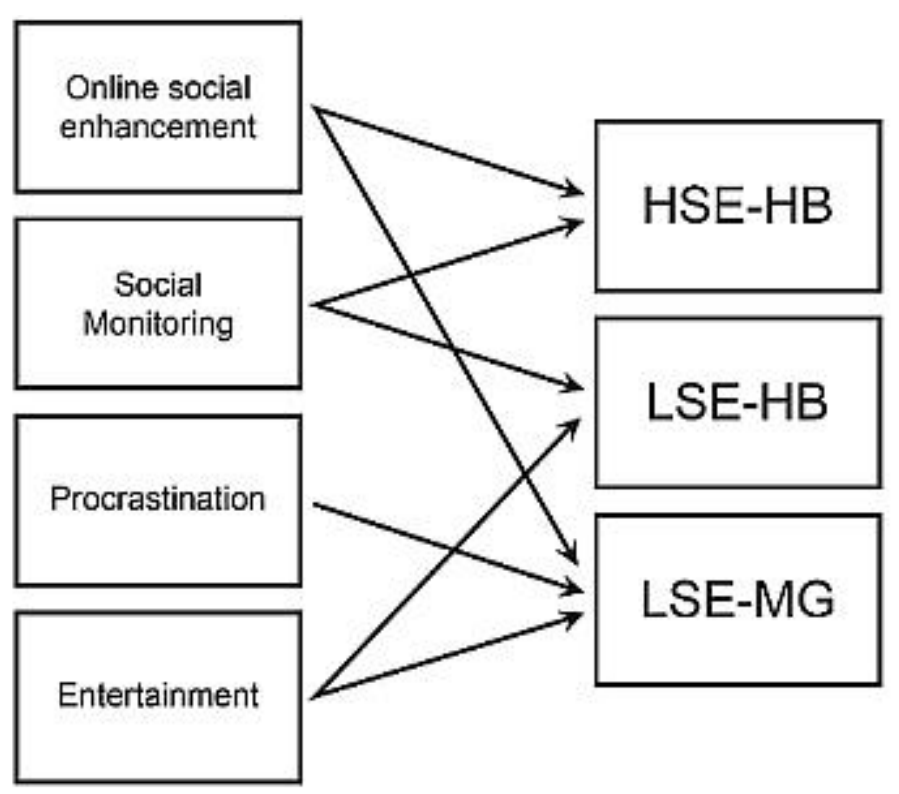

Figure 3. Proposed relationship between four potential pathways to problematic Facebook use and three potential types of problematic Facebook users.

\section{Limitations}

There were several limitations that hindered our results. As previously noted, the sample sizes for each cluster were small, which reduces ability to generalise the results presented here. While this is somewhat acceptable for the purposes of an exploratory pilot study, it is critical that further confirmatory research is performed before solid conclusions can be made.

In addition, the use of a survey was somewhat restricting; open-ended survey questions preclude the ability of the researcher to ask for clarification or further information regarding themes of interest. Due to this design weakness, some important symptoms were excluded from analysis (i.e., loss of control and online social enhancement). In future research studies, it would be useful to conduct focus groups or interviews to triangulate survey results and explore important themes more extensively. These more interactive methods of data collection would also allow scope to explore the possibility that there may be additional unique symptoms of problematic Facebook use (Ryan et al., 2016).

Finally, it is important to address the fact that the majority of problematic Facebook users identified in this study were female. One explanation for this trend is that women may be more likely than men to feel comfortable discussing mental health issues. On the other hand, it may be the case that women were more likely to meet the inclusion criteria for this study. Previous research has shown that women are heavier Facebook users than men (Kittinger, Correia, \& Irons, 2012; McAndrew \& Jeong, 2012; Thompson \& Lougheed, 2012), thus they may have been more inclined to take part in a study asking for respondents who spend too much time on Facebook. Unfortunately, there have been few similar studies with which to support this assertion. 


\section{Conclusion}

This study is one of the first to explore the potential typologies of problematic Facebook use. The results indicate that problematic Facebook use may indeed take different forms, and these are related to the types of activities that are performed. In this way, our study bolsters the model of compensatory internet use (Kardefelt-Winther, 2014). Of course, it is unlikely that problematic Facebook use will occur in every person who regularly engages in these kinds of activities for the purposes of mood alteration. In fact, it is expected that particular forms of underlying psychopathology are the key to the development of each type of problematic Facebook use.

For example, social anxiety might be an important pre-existing condition that leads to the proposed online social enhancement pathway of problematic Facebook use. Therefore, it is important for future research to ascertain which disorders display comorbidity with problematic Facebook use. It is also imperative that scholars examine the relevance of individual differences to the problematic Facebook use pathways proposed here, such as relationship status, self-esteem, and personality types. Finally, it should be established whether the proposed pathways are distinct to Facebook users, or whether they are also germane to other forms of online addiction.

\section{Acknowledgements}

Support for this publication was received through the RMIT Higher Degree by Research Publications Grant. Thanks to Joanne Ryan for assistance with the design of Figures 2 and 3.

\section{References}

American Psychological Association. (2000). Diagnostic and Statistical Manual of Mental Disorders (4th ed., text rev.). Washington, DC: Author.

American Psychological Association. (2013). Diagnostic and Statistical Manual of Mental Disorders (5th ed.). Arlington, VA: American Psychiatric Publishing.

Bozoglan, B., Demirer, V., \& Sahin, I. (2013). Loneliness, self-esteem, and life satisfaction as predictors of internet addiction: A cross-sectional study among Turkish university students. Scandinavian Journal of Psychology, 54, 313319. http://dx.doi.org/10.1111/sjop.12049

Brophy, L. M., Reece, J. E., \& McDermott, F. (2006). A cluster analysis of people on Community Treatment Orders in Victoria, Australia. International Journal of Law and Psychiatry, 29, 469-481.

http://dx.doi.org/10.1016/j.ijlp.2006.07.001

Buckner V. J. E., Castille, C. M., \& Sheets, T. L. (2012). The Five Factor Model of personality and employees' excessive use of technology. Computers in Human Behavior, 28, 1947-1953.

http://dx.doi.org/10.1016/j.chb.2012.05.014

Burns, R., \& Burns, R. (2008). Business research methods and statistics using SPSS. London, UK: Sage.

Çam, E., \& İşbulan, O. (2012). A new addiction for teacher candidates: Social networks. The Turkish Online Journal of Education Technology, 11(3), 14-19.

Caplan, S. E. (2005). A social skill account of problematic internet use. Journal of Communication, 55, 721-736. http://dx.doi.org/10.1111/j.1460-2466.2005.tb03019.x

Caplan, S. E. (2010). Theory and measurement of generalized problematic internet use: A two-step approach. Computers in Human Behavior, 26, 1089-1097. http://dx.doi.org/10.1016/j.chb.2010.03.012 
Clayton, R. B., Osborne, R. E., Miller, B. K., \& Oberle, C. D. (2013). Loneliness, anxiousness, and substance use as predictors of Facebook use. Computers in Human Behavior, 29, 687-693.

http://dx.doi.org/10.1016/j.chb.2012.12.002

Cohen, J. (1988). Statistical power analysis for the behavioral sciences (2nd ed.). Hillsdale, NJ: Lawrence Erlbaum Associates.

Davis, R. A. (2001). A cognitive-behavioral model of pathological internet use. Computers in Human Behavior, 17, 187-195. http://dx.doi.org/10.1016/S0747-5632(00)00041-8

Davis, R. A., Flett, G. L., \& Besser, A. (2002). Validation of a new scale for measuring problematic internet use: Implications for pre-employment screening. CyberPsychology \& Behavior, 5, 331-345.

http://dx.doi.org/10.1089/109493102760275581

DiChiara, C. A. (2010). A comparison of social capital and the problematic use of massively multiplayer online games. [Doctoral dissertation]. Retrieved from ProQuest Information \& Learning. (UMI: 3415697)

Digre, E. I., Reece, J., Johnson, A. L., \& Thomas, R. A. (2009). Treatment response in subtypes of borderline personality disorder. Personality and Mental Health, 3, 56-67.

Facebook (2016). Facebook Newsroom: Company Info. Retrieved from newsroom.fb.com/company-info/ on 17 July, 2016.

Goldberg, L. R. (1990). An alternative "description of personality": The big-five factor structure. Journal of Personality and Social Psychology, 59, 1216-1229. http://dx.doi.org/10.1037//0022-3514.59.6.1216

Greenfield, D. N. (1999). Psychological characteristics of compulsive internet use: A preliminary analysis. CyberPsychology \& Behavior, 2, 403-414. http://dx.doi.org/10.1089/cpb.1999.2.403

Griffiths, M. D. (1999). Internet addiction: Fact or fiction? Psychologist, 12, 246-250.

Griffiths, M. (2000). Internet addiction - Time to be taken seriously? Addiction Research, 8, 413-418.

Griffiths, M. D. (2012). Facebook addiction: Concerns, criticism, and recommendations - A response to Andreassen and colleagures. Psychological Reports, 110, 518-520.

http://dx.doi.org/10.2466/01.07.18.pr0.110.2.518-520

Griffiths, M. D., Kuss, D. J., \& Demetrovics, Z. (2014). Social networking addiction: An overview of preliminary findings. In K. P. Rosenberg \& L. C. Feder (Eds.), Behavioral addictions: Criteria, evidence, and treatment (pp. 119141). London, UK: Academic Press.

Hawi, N. S. (2012). Internet addiction among adolescents in Lebanon. Computers in Human Behavior, 28, 10441053. http://dx.doi.org/10.1016/j.chb.2012.01.007

Hong, F., Huang, D., Lin, H., \& Chiu, S. (2014). Analysis of the psychological traits, Facebook usage, and Facebook addiction model of Taiwanese university students. Telematics and Informatics, 31, 597-606.

http://dx.doi.org/10.1016/j.tele.2014.01.001

Liu, H., \& Wang, H. (2012). Mobile phone addiction tendency and loneliness in college students. Chinese Mental Health Journal, 26, 66-69. Retrieved from http://search.proquest.com/docview/1285631293?accountid=13552

Hsu, S. H., Wen, M. H., \& Wu, M. C. (2009). Exploring user experiences as predictors of MMORPG addiction. Computers \& Education, 53, 990-999. 
Hussain, Z., \& Griffiths, M. D. (2009). Excessive use of Massively Multi-Player Online Role-Playing Games: A pilot study. International Journal of Mental Health and Addiction, 7, 563-571. http://dx.doi.org/10.1007/s11469-009-

9202-8

Indian, M., \& Grieve, R. (2014). When Facebook is easier than face-to-face: Social support derived from Facebook in socially anxious individuals. Personality and Individual Differences, 59, 102-106.

http://dx.doi.org/10.1016/j.paid.2013.11.016

Jones, B. T., Corbin, W., \& Fromme, K. (2001). A review of expectancy theory and alcohol consumption. Addiction, 96, 57-72. http://dx.doi.org/10.1080/09652140020016969

Kardefelt-Winther, D. (2014). A conceptual and methodological critique of internet addiction research: Towards a model of compensatory internet use. Computers in Human Behavior, 31, 351-354.

http://dx.doi.org/10.1016/j.chb.2013.10.059

Kittinger, R., Correia, C. J., \& Irons, J. G. (2012). Relationship between Facebook use and problematic internet use among college students. Cyberpsychology, Behavior, and Social Networking, 15, 324-327.

http://dx.doi.org/10.1089/cyber.2010.0410

Kotov, R., Gamez, W., Schmidt, F., \& Watson, D. (2010). Linking "big" personality traits to anxiety, depressive, and substance use disorders: A meta-analysis. Psychological Bulletin, 136, 768-821.

http://dx.doi.org/10.1037/a0020327

Kuss, D. J., \& Griffiths, M. D. (2011). Online social networking and addiction-A review of the psychological literature. International Journal of Environmental Research and Public Health, 8, 3528-3552. Retrieved from http://search.proquest.com/docview/899323305?accountid=13552

Kuss, D. J., Griffiths, M. D., Karila, L., \& Billeux, J. (2013). Internet addiction: A systematic review of epidemiological research for last decade. Current Pharmaceutical Design, 20, 4026-4052.

Landis, J. R., \& Koch, G. G. (1977). The measurement of observer agreement for categorical data. Biometrics, 33(1), 159-174.

Lee, Z. W. Y., Cheung, C. M. K., \& Thadani, D. R. (2012). An investigation into the problematic use of Facebook. Proceedings of the 45th Hawaii International Conference on System Sciences, 1768-1776.

http://dx.doi.org/10.1109/HICSS.2012.106

McAndrew, F. T., \& Jeong, H. S. (2012). Who does what on Facebook? Age, sex, and relationship status as predictors of Facebook use. Computers in Human Behavior, 28, 2359-2365.

http://dx.doi.org/10.1016/j.chb.2012.07.007

Mooi, E., \& Sarstedt, M. (2011). Cluster analysis. A concise guide to market research. Berlin, Germany: Springer.

Przybylski, A. K., Murayama, K., DeHaan, C. R., \& Gladwell, V. (2013). Motivational, emotional, and behavioral correlates of fear of missing out. Computers in Human Behavior, 29, 1841-1848.

http://dx.doi.org/10.1016/j.chb.2013.02.014

Ryan, T., Chester, A., Reece, J., \& Xenos, S. (2014). The uses and abuses of Facebook: A review of Facebook addiction. Journal of Behavioral Addictions, 3, 133-148. http://dx.doi.org/10.1556/jba.3.2014.016

Ryan, T., Chester, A., Reece, J., \& Xenos, S. (2016). A qualitative exploration of Facebook addiction: Working toward construct validity. Addicta: The Turkish Journal on Addictions, 3, 55-76. 
Ryan, T., \& Xenos, S. (2011). Who uses Facebook? An investigation into the relationship between the Big Five, shyness, narcissism, loneliness, and Facebook usage. Computers in Human Behavior, 27, 1658-1664.

http://dx.doi.org/10.1016/j.chb.2011.02.004

Schoenfeld, W. N., Cumming, W. W., \& Hearst, E. (1956). On the classification of reinforcement schedules. Proceedings of the National Academy of Sciences, 42, 563-570. http://dx.doi.org/10.1073/pnas.42.8.56

Sim, T., Gentile, D. A., Bricolo, F., Serpelloni, G., \& Gulamoydeen, F. (2012). International Journal of Mental Health and Addiction, 10, 748-769. http://dx.doi.org/10.1007/s11469-011-9369-7

Smith, C. (2013a, December 1). How many people use 340 of the top social media, apps \& services? [Web log post]. Retrieved from http://expandedramblings.com/index.php/resource-how-many-people-use-the-top-socialmedia

Smith, S. R. (2013b). The development and validation of the Problematic Online Gaming Scale (POGS): An analysis of Facebook gamers. [Doctoral dissertation]. Available from ProQuest Dissertations and Theses Database. (UMI: 3564698)

Thompson, S. H., \& Lougheed, E. (2012). Frazzled by Facebook? An exploratory study of gender differences in social network communication among undergraduate men and women. College Student Journal, 46, 88-98.

Tonioni, F., D'Alessandris, L., Lai, C., Martinelli, D., Corvino, S., Vasale, M., . . Bria, P. (2012). Internet addiction: Hours spent online, behaviors and psychological symptoms. General Hospital Psychiatry, 34, 80-87.

http://dx.doi.org/10.1016/j.genhosppsych.2011.09.013

van den Eijnden, R. J. J. M., Meerkerk, G.-J., Vermulst, A. A., Spijkerman, R., \& Engels, R. C. M. E. (2008). Online communication, compulsive internet use, and psychosocial well-being among adolescents: A longitudinal study. Developmental Psychology, 44, 655-665. http://dx.doi.org/ 10.1037/0012-1649.44.3.655

Wan, C. (2009). Gratifications and loneliness as predictors of campus-SNS websites addiction and usage pattern among Chinese college students. [Master's thesis]. Retrieved from http://pg.com.cuhk.edu.hk/pgp_nm/projects/2009/Wan\%20Sisi\%20Candy.pdf

Wilson, K., Fornasier, S., \& White, K. M. (2010). Psychological predictors of young adults' use of social networking sites. Cyberpsychology, Behavior, and Social Networking, 13, 173-177. http://dx.doi.org/10.1089/cyber.2009.0094

Yang, Y., Li, L., \& Mingxin, L. (2006). The relationship between adolescents' conscientiousness, internet service preference and internet addiction. Psychological Science (China), 29, 947-950. Retrieved from http://search.proquest.com/docview/621476484?accountid=13552

Young, K. S., Pistner, M., O'Mara, J., \& Buchanan, J. (1999). Cyber-disorders: The mental health concern for the new millennium. CyberPsychology \& Behavior, 2, 475-479. http://dx.doi.org/10.1089/cpb.1999.2.475

Yu, S. C., Hsu, W. H., Yu, M. N., \& Hsu, H. Y. (2012). Is the use of social networking sites correlated with internet addiction? Facebook use among Taiwanese college students. World Academy of Science, Engineering and Technology, 68, 1659-1661.

Zaremohzzabieh, Z., Samah, B. A., Omar, S. Z., Bolong, J., \& Kamarudin, N. A. (2014). Addictive Facebook Use among University Students. Asian Social Science, 10(6), 107-116. http://dx.doi.org/10.5539/ass.v10n6p107

Zhou, S. X., \& Leung, L. (2012). Gratification, loneliness, leisure boredom, and self-esteem as predictors of SNSgame addiction and usage pattern among Chinese college students. International Journal of Cyber Behavior, Psychology and Learning, 2(4), 34-48. http://dx.doi.org/10.4018/ijcbpl.2012100103 


\section{Appendix. Problematic Facebook Use Survey}

What is your sex?

- Male

- Female

What country do you live in?

- Australia

- Canada

- Ireland

- New Zealand

- United Kingdom

- United States of America

- Other (please specify)

How old are you?

- 17 or under

- 18 or over (please specify your actual age)

Do you currently have a Facebook account?

- Yes

- No

On average, how much time per day do you spend on Facebook (for non-work related purposes)?

- 30 minutes or less

- 31-60 minutes

- $1-2$ hours

- 2-4 hours

- 5-6 hours

- 6-8 hours

- More than 8 hours

How often do you use Facebook on devices other than your computer (for non-work related purposes)?

- Never

- Rarely

- Sometimes

- Often

What do you generally spend most of your time doing when you are using Facebook? (i.e., commenting on Friend's posts, looking at Photos, playing Games, etc.)?

Do you ever think about Facebook when you are not using it?

- Yes

- $\mathrm{No}$ 
What sort of thoughts do you have about Facebook when you're not using it?

The following questions ask about the mood or frame of mind you are in when you engage in various activities on Facebook. Please pay attention to the underlined section of each question to determine which activity is being referred to.

Would you say that you are generally in a particular mood or frame of mind when you decide to check Facebook?

- Yes

- No

Please explain what sort of mood or frame of mind you are generally in when you decide to check Facebook:

Would you say that you are generally in a particular mood or frame of mind when you decide to update your status on Facebook?

- Yes

- No

Please explain what sort of mood or frame of mind you are generally in when you decide to update your status on Facebook:

When answering the following question, please respond in terms of how you would usually spend most of your time when using Facebook (i.e., looking at your News Feed, playing Games, viewing Photos, etc.).

Would you say that you are generally in a particular mood or frame of mind when you are using Facebook?

- Yes

- No

Please explain what sort of mood or frame of mind you are generally in when you are using Facebook.

Please indicate your level of agreement with the following question:

My Facebook usage is motivated by a desire to be social, or to feel connected to others.

- Strongly Disagree

- Disagree

- Neither Agree nor Disagree

- Agree

- Strongly Agree 
Does socialising on Facebook feel different to you than socialising in real life?

- Yes

- No

Please explain how socialising on Facebook is different to socialising in real life:

Have you ever been in a situation when you couldn't or didn't access Facebook for a long period of time (i.e., a week or longer)?

- Yes

- No

Why did you stop accessing Facebook during that time?

How long were you without Facebook access?

How did you feel during this time?

How do you think you would feel if you couldn't access Facebook for a long period of time (i.e., a week or longer)?

Can you think of any instances when your Facebook use interfered with your normal daily activities (i.e., it distracted you from work, study, or social events)?

- Yes

- No

Please provide an example of any such instances:

Can you think of any instances when your Facebook use has caused problems with your personal relationships?

- Yes

- No

Please provide an example of any such instances: 
Have you ever been told by someone that you spend too much time using Facebook, or that you use Facebook in a problematic way?

- Yes

- No

Please provide an example of any such instances:

\section{How concerned are you about your Facebook use?}

- Not at all concerned

- Mildly concerned

- Moderately concerned

- Very concerned

- Extremely concerned

Please explain what concerns you about your Facebook use:

Thank you for your time.

\section{Correspondence to:}

Tracii Ryan

Faculty of Education

Monash University

Clayton, Victoria

Australia 3800

Email: tracii.ryan(at)monash.edu

\section{About authors}

Tracii Ryan, PhD, is a Research Fellow in the Faculty of Education at Monash University. With a background in psychology, her research broadly focuses on the motivations, outcomes, and individual differences associated with the use digital technologies, both in and out of an educational environment.

John Reece, PhD, is Professor of Psychological Science at the Australian College of Applied Psychology in Melbourne, Australia. He has special expertise in the area of research methods and quantitative data analysis, particularly in the specific area of clinical trials. His own research focuses on the psychology of resilience, psychological research methods, and the scholarship of teaching and learning.

Andrea Chester, PhD, has a background in psychology education and practice, with more than 20 years' experience as an academic. Over the years Andrea has taught across the psychology curriculum, with a particular interest in first year and transition issues and she continues to teach in both first and third year. Her research has focused on online interventions.

Sophia Xenos, $\mathrm{PhD}$, is an experienced academic and clinical psychologist who teaches psychological theory at the undergraduate level and clinical skills at the postgraduate level. Sophia's primary research interest is in the field of clinical psychology, with a particular focus on psychopathology in the online domain. 